\title{
A FAMILY OF MEROMORPHICALLY MULTIVALENT FUNCTIONS
} WHICH ARE STARLIKE WITH RESPECT TO $k$-SYMMETRIC POINTS

\author{
JiN-Lin LIU, H. M. SRIVASTAVA AND YUAN YUAN
}

Abstract. In this paper, two new subclasses $\mathscr{R}_{p, k}(\lambda, A, B)$ and $\mathscr{T}_{p, k}(\lambda, A, B)$ of meromorphically multivalent functions starlike with respect to $k$-symmetric points are studied. Distortion bounds, inclusion relations and convolution properties for each of these classes are obtained.

Mathematics subject classification (2010): Primary 30C45.

Keywords and phrases: Meromorphically multivalent functions, Hadamard product (or convolution), distortion bounds, inclusion relations, convolution properties, subordination properties, symmetric points.

\section{REFERENCES}

[1] N. E. Cho, O. S. Kwon AND S. OwA, Certain subclasses of Sakaguchi functions, Southeast Asian Bull. Math. 17 (1993), 121-126.

[2] S. A. Halim, Functions starlike with respect to other points, Internat. J. Math. \& Math. Sci. 14 (1991), 451-456.

[3] R. PaVATham And S. Radha, On $\alpha$-starlike and $\alpha$-close-to-convex functions with respect to $n$ symmetric points, Indian J. Pure Appl. Math. 16 (1986), 1114-1122.

[4] C. Pommerenke, Univalent functions, With a chapter on quadratic differentials by Gerd Jensen, Studia Mathematica/Mathematische Lehrbücher, Band XXV, Vandenhoeck \& Ruprecht, Göttingen, 1975.

[5] St. Ruscheweyh And T. Sheil-Small, Hadamard products of schlicht functions and the PólyaSchoenberg conjecture, Comment. Math. Helv. 48 (1973), 119-135.

[6] K. SakAguCHI, On a certain univalent mapping, J. Math. Soc. Japan 11 (1959), 72-75.

[7] H. M. SRivastava, A. Y. LAShin And B. A. Frasin, Starlikeness and convexity of certain classes of meromorphically multivalent functions, Theory Appl. Math. Comput. Sci. 3 (2013), 93-102.

[8] H. M. SRivastaVA, D.-G. YANG AND N.-E. XU, Some subclasses of meromorphically multivalent functions associated with a linear operator, Appl. Math. Comput. 195 (2008), 11-23.

[9] J. StantiewiCs, Some remarks on functions starlike with respect to symmetric points, Ann. Univ. Mariae Curie-Skłodowska Sect. A 19 (1965), 53-59.

[10] H. TAng, H. M. SRivastava, S.-H. Li AND L.-N. Ma, Third-order differential subordination and superordination results for meromorphically multivalent functions associated with the Liu-Srivastava operator, Abstr. Appl. Anal. 2014 (2014), Article ID 792175, 1-11.

[11] Z.-G. WAng, H. M. SRIVAStava And S.-M. YuAn, Some basic properties of certain subclasses of meromorphically starlike functions, J. Inequal. Appl. 2014 (2014), Article ID 2014:29, 1-12.

[12] Z.-G. WANG, C.-Y. GAO AND S.-M. YUAN, On certain subclasses of close-to-convex and quasiconvex functions with respect to $k$-symmetric points, J. Math. Anal. Appl. 322 (2006), 97-106.

[13] Z. Wu, On classes of Sakaguchi functions and Hadamard products, Sci. Sinica Ser. A 30 (1987), $128-135$.

[14] N.-E. XU AND D.-G. YAnG, Some classes of analytic and multivalent functions involving a linear operator, Math. Comput. Modelling 49 (2009), 955-965.

[15] S.-M. YUAN AND Z.-M. LiU, Some properties of $\alpha$-convex and $\alpha$-quasiconvex functions with respect to $n$-symmetric points, Appl. Math. Comput. 188 (2007), 1142-1150. 